\title{
Learning from Experience: Case Studies of the Hyper-X Project
}

\author{
Curtis Peebles ${ }^{1}$ \\ Tybrin/Dryden Flight Research Center, Edwards AFB, CA 93523
}

\begin{abstract}
The Hyper-X project (X-43A) provides a number of "lessons learned" which can be applied to other aerospace project. The specific areas examined were the selection of the goals of the Hyper-X. How the technical unknowns and assumptions were handled. The final lesson was the ambiguous nature of risk assessment, and how trying to remove a technical unknown can have unintended consequences.
\end{abstract}

\section{Nomenclature}

$\begin{array}{ll}\text { CFD } & =\text { Computational Fluid Dynamics } \\ \text { FAS } & =\text { Fin Actuation System } \\ \text { HXLV } & =\text { Hyper-X Launch Vehicle } \\ \text { NASP } & =\text { National Aerospace Plane } \\ \text { PID } & =\text { Parameter Identification }\end{array}$

\section{Introduction}

$\mathrm{T}$ HE Hyper-X project made the first flight tests of an airframe integrated scramjet-powered vehicle. It was launched from NASA's B-52B mothership, and was accelerated to the test speed by a modified Pegasus booster. The X-43A research vehicle separated from the Pegasus, ignited its scramjet, and began the engine test. Of the three launch attempts, two were successful. The second vehicle demonstrated that an integrated scramjet could produce more thrust than drag at a speed near Mach 7; the third vehicle was able to cruise at almost Mach 10.

This paper will undertake three case studies of the Hyper-X project. The first deals with the definition of the project. Specifically what did it hope to accomplish. The second deals with the different way two separate technical issues were dealt with. And the third examines the consequences of attempting to fix a potential hardware defect. Each of these experiences has relevance for other aeronautical and space projects.

\section{What do you want to do?}

This is the most basic question possible, arguably the least obvious, yet the most important. Unless you know what it is you want to do, you cannot intelligently plan anything else. The Hyper-X project would flight test a scramjet engine. The designs of both vehicle and scramjet were based on ground tests and theoretical analysis. The Hyper-X would show if these results were valid, and move hypersonic technology from the laboratory to actual flight.

Once the Hyper-X project was approved the broad outlines had to be transformed into a detailed development and test schedule. In the process, a wide range of decisions had to be made. Was the vehicle to use a ground-launched or an air-launched booster? How many flights would be made? How big would the vehicle be?

At the time, no ground-launched booster could meet the requirements without major modification, posing technical and cost risks. Accordingly, an air launch from the B-52 was selected, using a modified Pegasus first stage called the Hyper-X Launch Vehicle (HXLV). ${ }^{1}$

The number of flights was also an issue. Originally, there were to be four flights - a Mach 7 flight to test the engine's ability to produce more thrust than the vehicle drag, a Mach 5 flight to demonstrate the engine's ability to shift from the subsonic combustion of a ramjet to supersonic combustion of a scramjet, and a pair of Mach 10 flights

${ }^{1}$ Historian, Hyper-X, PO Box 273/Mail Stop, 4829.

American Institute of Aeronautics and Astronautics 092407 
to demonstrate cruise flight. Early on, as the project developed and costs increased, the Mach 5 flight was dropped, as it had a lesser priority. Two Mach 7 flights and a single a Mach 10 flight would be made, with the same goals as before. $^{2}$

The X-43A vehicle size was another critical issue, as it affected the booster and scramjet performance, cost, and other program aspects. Two options were available - a ten-foot vehicle or a twelve-foot version. Project managers selected the twelve-foot design, as it had a small performance gain over the shorter vehicle, more internal space for systems, and the larger size did not cause a major increase in costs. Packing all the equipment into this limited volume was difficult, but a program decision was made to make no changes the vehicle's length or other dimensions.

This avoided a potentially serious problem. If the size had been increased each time a problem with systems integration appeared, it would have required a new design iteration. Costs would grow, and progress toward a flight would be stalled. For all the engineers' difficulties in packaging the system, this was viewed by program personnel as a critical decision. ${ }^{3}$

A final issue is a tendency to expand a project's research activities with "nice to have" features. On the X-43A, proposals were made to recover the vehicle after the flight. This was to determine the effects on the vehicle and scramjet of its hypersonic flight. But the vehicle was never designed for recovery, and any attempt would require extensive modifications and would endanger the primary mission. One proposal was to put retractable skids on the top of the vehicle. It would then roll upside down and land on a runway. Project management finally said recovery was off the table.

This is not to say "add-on" studies were completely avoided. After the scramjet engine burn was completed, the X-43A made parameter identification (PID) maneuvers for hypersonic and supersonic aerodynamic data. Unlike the landing proposal, these did not compromise the basic mission goal. If the vehicle survived to this point, the scramjet test had been accomplished, and maneuvers were a free bonus. ${ }^{4}$

The X-43A serves as an example of a tightly focused project to prove the feasibility of a technology. In this case, the goal was testing the feasibility of a scramjet engine. It did not diverge from this goal, and, as a result, avoided many problems which could have doomed the effort.

\section{Are you worrying about what you should be worrying about?}

Once a project has started, the managers and engineers are beset by a seemingly endless series of problems, issues, errors, test failures, what if, and maybes. What has to be dealt with to prevent failure, what needs only limited work, and what do you just accept?

From the very beginning, the separation of the X-43A from the modified Pegasus first stage was a major worry. This would occur at a dynamic pressure of about 1,000 pounds per square foot. Just as important, the X-43A weighed about 3,000 pound and was located at the forward end of the booster. When the test vehicle separated, the HXLV's center of gravity would suddenly shift aft. The HXLV might pitch up and strike the aft end of the X-43A before it cleared the booster, sending it out of control.

Finally, as the separation began, a gap would open between the wedge-shaped adapter and the aft end of X-43A. There was concern that this would create a potentially nonlinear and dynamic flowfield in the gap, again threatening a loss of control of the X-43A. There was no past experience to draw on, as no separation of nonsymmetrical shapes had been attempted in so complex a flowfield and at so high a dynamic pressure.

Attempts to solve the problem produced both serious suggestions and "bright ideas." One approach was to avoid the separation problem entirely, by firing the booster on a suborbital trajectory. The X-43A would separate at zero dynamic pressure, reenter, and, once it had slowed and descended to the proper speed and altitude, begin the scramjet test. But the heat load the vehicle would experience was too high for it to withstand such a flight profile.

One of the "bright ideas" was to attach a long dummy fairing to the Pegasus first stage. This would render it similar in shape to the standard three-stage booster. The X-43A would not be mounted on the nose of the fairing, but semi-submerged and upside down in the fairing's underside. At separation, the X-43A would fall free of the booster as it pitched up. The X-43A would roll upright and ignite the scramjet. This plan was discarded as impractical.

The design engineers finally pursued was far simpler. The separation would begin with the firing of four explosive bolts that anchored the X-43 to the adapter, followed by two pistons pushing the X-43A clear of the adapter. The wedge-shaped adapter would swing down to a $90^{\circ}$ angle as a single piece to clear the wings. This device was referred to as the "drop jaw." This design underwent extensive wind tunnel, computational-fluid-dynamics (CFD) simulations, and Monte Carlo analysis. These used different wind tunnels, different computer programs, different 
variables of atmospheric conditions, and ground tests using cement blocks to simulate the booster and X-43A. Finally, an actual flight X-43A and adapter were used in a ground test.

These tests pointed to a problem. When the drop jaw moved to the $90^{\circ}$ angle, shock waves formed which struck the aft end and nozzle area of the X-43A, causing it to pitch down and lose control. The solution was to leave the drop jaw fixed. The simulations indicated the airflow in the X-43A/adapter gap as it opened would not cause problems. Despite all the work, uncertainty remained about how accurate the predictions were. The real answer would only be known when separation was attempted. ${ }^{5}$

The second of the two issues was the modified HXLV booster used for the Mach 7 flights. With the standard launch conditions, the HXLV had a burnout speed of Mach 10. Somehow, the excess energy had to be dissipated to reduce the separation speed to Mach 7.

The first approach was to remove about 1,300 pounds of solid propellant, which would allow a launch from the B52 at the normal 40,000 foot altitude and Mach 0.8 speed, and result in a Mach 7 burnout speed. This option was rejected by the program engineers, who saw it as a second research program, putting the success of the X-43A at risk. The other option was a launch at a non-standard altitude of 20,000 feet and a slower speed of Mach 0.5. The question was whether this second option would work, or if the more complex and risky offloading was required.

Two approaches could be used in analyzing these issues. The first was to conduct a complete design review of the two options. During the initial planning, however, a decision was made by project managers to use the existing Pegasus database and the wind tunnel model to qualify the new HXLV configuration. The focus would be on Hyper$\mathrm{X}$ specific issues, and solutions would rely as much as possible on existing data. Accordingly, limited testing was done using the existing Pegasus wind tunnel model, fitted with an adapter and X-43A. This revealed no issues with the lower/slower launch profile, and this launch profile was approved for the Mach 7 flights. ${ }^{6}$

On June 2, 2001, the first Hyper-X launch ended in failure 13.5 seconds after launch from the B-52 as the booster's fins broke off, sending the HXLV spiraling out of control toward the Pacific Ocean. The mishap investigation board determined that the HXLV had become unstable at transonic speed. The standard Pegasus was also unstable at transonic speeds, but due to its higher launch speed and altitude, the rocket accelerated through the transonic region before instability overwhelmed the control system. The HXLV's lower/slower launch conditions gave it a slower acceleration, leaving it to fly longer in the transonic realm, and causing the loss of control. The HXLV's fin actuation system (FAS) was also unable to produce enough torque to move the rudders against higherthan-predicted dynamic pressure. The instability and the high rudder loads had not been predicted by the analytical models of the booster. ${ }^{7}$

Here were two problems which engineers dealt with in different ways. The separation issue was the subject of numerous tests, using different CFD programs, different wind tunnels, models, and other tests. In retrospect, this testing dragged out the program, delaying the flight, and yet was still unable to give a definitive answer about the risk of failure.

In contrast, the risks of the lower/slower HXLV launch profile received only limited attention. Only those aspects related to the Hyper-X were examined, and this review of the new launch profile was based on the existing flight models. Wind tunnel testing of the HXLV was done, but with a modified existing Pegasus model, using linear interpolations to build the database. This was insufficient to detect the problems which doomed the launch. After the failure, the cause was soon apparent.

The project personnel were concerned about separation because of the unknowns and exotic nature of the event. The new launch profile was accepted because of confidence in the booster, and because the limited testing indicated no reasons for concern. There seemed no reason to ask "are you worrying about what you should be worrying about."

\section{It's Broke, Don't Fix It}

Following the loss of the first Hyper-X, solid fuel was removed from the second HXLV to allow a Mach 7 burnout following a standard 40,000 foot/Mach 0.8 launch. Despite the new launch profile, simulations indicated the possibility that the FAS could again fail to provide sufficient torque. Project management decided that the FAS' torque had to be increased. This was viewed as a "simple fix," unlike the propellant off-loading of the HXLV, which was still viewed with concern.

The FAS modification involved adding a second motor. This raised the torque from 1,800 foot-pounds to over 3,000 foot pounds. Even in the worst case simulations, the modification provided a 25 to $30 \%$ torque margin. Adding the second motor, however, required replacing several electronic components with new designs. Initial testing went well until a cold-soak test. The actuator was commanded to slew the fin at a high rate. Instead, the 
actuator suffered a "latch up." Had this occurred in flight, the fin would have stopped responding and the mission would have failed.

To further complicate the problem, when diagnostic equipment was hooked up to the FAS, the problem vanished. After a great deal of work, the cause was finally traced to excessive electronic noise. The fix itself was simple. Transistors were added to diminish (but not eliminate) the noise. The modified FAS subsequently passed the ground tests, having caused a six-month delay. If the failure occurred, it would be when the HXLV pitched up into the climb. This was the only time during the burn when the high slew rates occurred. But while this worked; the exact cause of the problem was not clear. ${ }^{8}$

The second Hyper-X flight was made on March 27, 2004. Despite the unknowns of the off-loaded booster, stability through transonic speeds, the FAS, the separation sequence, and airflow between the adapter and X-43A, the launch and boost were successful. The scramjet ignited and accelerated the vehicle. The engine's performance was close to that predicted. After the ten-second burn, the X-43A performed the aerodynamic test maneuvers. The top speed was Mach 6.83, making the X-43A the first hypersonic airbreathing vehicle to fly.

With the successful completion of the second flight, attention shifted to the third flight. This had as its goal cruise flight at nearly Mach 10. The flight was planned for September. Such a short turnaround was ambitious, but project personnel thought it was possible. One reason was the solution of the FAS problem. ${ }^{9}$

During the first week of June, two FAS power boards failed undergoing their cold testing. When replacement boards were tested, one of the channels latched up. This occurred at room temperatures, not during the cold testing. Testing indicated these boards had more electronic noise than to the flight 2 boards. The cause was traced to the use of components from a different lot number. The individual differences were enough to cause a latch up. ${ }^{10}$

The problem was solved with "more of the same" fix, and initial tests were successful. During an acceptance test in August, a high current switching component failed, and burned up a control board. Again, project engineers began an investigation. As before, the exact cause could not be pinpointed. Their failure analysis indicated that the electronic noise had caused both pairs of field effect transistors to switch on. These devices were responsible for moving the fin. When both were activated, they shorted out and melted. Hardware modifications, careful selection of components, and changes in test procedures were made to prevent a reoccurrence during Flight 3 . The FAS successfully passed the final ground testing, but the difficulties resulted in a two-month flight delay. ${ }^{11}$

However, project personnel realized the FAS could fail at anytime after being activated two minutes before launch. Moreover, the Flight 2 FAS had had the same flaw. They had dodged the bullet once without knowing it. Would they be lucky next time?

To make matters more difficult for the team, this knowledge was of little comfort or value: there was neither money nor time to design a new FAS. They had to fly with what they had.

The third flight, made on November 16, 2004, went off without a hitch. The launch was successful and the FAS performed without any problems. The X-43A separated from the HXLV and ignited the scramjet engine. The scramjet produced enough thrust to counter the drag. The eleven-second burn produced far more scramjet data at high Mach numbers than had the previous four decades. Top speed was Mach 9.68.

The irony was that after the endless troubles fixing the FAS, the two successful flights never came close to exceeding the predicted dynamic pressure because of the standard launch conditions. They would have been successful with the standard Pegasus FAS. ${ }^{12}$ While "if it ain't broke don't fix it" is the normal phrase used, in this case, trying to fix the problem almost killed the Hyper-X project.

\section{Conclusion}

What then of the three case studies? Case 1, the question of what you want to do, was answered. The Hyper-X began and remained a tightly focused research project, to answer a very basic question - will a scramjet work in flight. Despite four decades of effort, the two launches represented the first actual flight data on scramjet operations.

Recall Apollo's goal - to land a man on the Moon and return him safely to the Earth within the decade. Seventeen words which defined every engineering aspect of the project. In contrast, the National Aerospace Plane (NASP) was ill-defined. It was all things to all people - a single-stage-to-orbit vehicle, a transpacific hypersonic airliner, an experimental research vehicle, and a technological development and research program. NASP was based on projections of possible technologies, high-hopes, and over optimism. While NASP advanced the state of the art, and led to the Hyper-X project, it could not produce a workable vehicle. The subsequent hypersonic effort learned this lesson. 
The Air Force scramjet research program, the X-51, is focused on extending the scramjet burn time from seconds to several minutes. As with the X-43A, there would be value in recovering the X-51 after flight. As with the Hyper$\mathrm{X}$, a deliberate decision was made to forgo recovery. Charles Brink, the X-51 program manager, commented: "We would love to recover the vehicles." However, like the Hyper-X, the X-51 is so packed with equipment a recovery capability would be too expensive and "design-wise very tough.",

When a project is a proof of concept test with a limited goal, this narrow focus is preferable. At the same time, the demonstration must provide value for the cost. If it is perceived as too narrow in its goals, support may vanish as problems occur.

Case 2 points out the limitations of "off-the-shelf" technology. The Pegasus was the only viable option as the Hyper-X booster. All the potential ground-launched boosters required an extensive and costly development program. A new booster would have been unproven, carrying a high risk of failure. There was no sense in incurring such risks when a proven booster existed which could meet the mission requirements.

Yet the HXLV was not the Pegasus booster either. It was modified for the X-43A launch, and was flying a profile for the Mach 7 flight which was very different from a satellite launch. Yohan Lin, a NASA test engineer on the Hyper-X project, noted: "Whenever you tweak a system that's already working you're always asking for trouble."

Procedures exist to qualify modifications to existing systems, whether major or minor. In the case of the HXLV, these showed no indications of problems. In fact, however, the testing was insufficient to discover the flaws which lead to the Flight 1 failure. Once the accident occurred, the flaws were apparent.

On the HXLV, the engineers tested what they thought needed testing and accepted as fact what was already fact and known. Ironically, the Wright Brothers followed this same procedure, with the same results. In designing the airfoils for their early gliders, they used Otto Lilienthal's tables of lift. He had, after all successfully flown gliders, indicating his data was accurate. Only after the initial flight tests, did the Wright brothers find that Lilienthal's airfoil tables were wrong.

In retrospect, a complete design review of the HXLV should have been made. Of course, in retrospect, there should also have been a reevaluation of using atmospheric pure oxygen during pad checkouts of the Apollo Command Module. As with the Apollo fire, the loss of the first Hyper-X launch caused a prolonged reevaluation of the project. The Mishap Investigation Board not only looked at the root causes of the accident, but sought any weakness which might cause another failure.

Case 3 points out the ambiguous nature of risk assessments. Flight 1 failed in part because the FAS could not produce sufficient torque to overcome the higher-than-predicted dynamic pressure. Following the loss of flight 1 project personnel believed that if the second flight also failed, the Hyper-X project would be cancelled outright. ${ }^{14}$

On one hand the FAS fix could be dismissed as being too careful. However, a possibly fatal problem was apparent, the risk was deemed credible, especially after the loss of Flight 1, and a solution was seen as both needed and easy. The difficulty of the solution only became apparent in retrospect.

As with much in life, an aerospace project is an endless series of decisions. How these decisions will turn out is unknown before hand, and totally obvious in retrospect. The lessons learned from the Hyper-X can be applied to other, similar projects. They also underline something our risk averse society does not want to hear. The reality is that failure often teaches more than success. Failure tells you what you don't know.

\section{References}

\footnotetext{
${ }^{1}$ Philip J. Joyce, John B. Pomroy, and Laurie Grindle, “The Hyper-X Launch Vehicle: Challenges and Design Considerations for Hypersonic Flight Testing,” AIAA Paper 2005-3333, p. 3-6.

${ }^{2}$ Paul Reukauf history interview, p. 26-29. NASA Dryden Flight Research Center History Office.

${ }^{3}$ Vincent L. Rausch, Charles R. McClinton, and J. Larry Crawford, "Hyper-X: Flight Validation of Hypersonic Airbreathing Technology," p. 2, and Griff Corpening history interview, December 20, 2004, p. 22, 32, 33. NASA Dryden Flight Research Center History Office.

${ }^{4}$ Reukauf history interview, p. 29-32.

${ }^{5}$ David E. Reubush, "Hyper-X Stage Separation - Background and Status," AIAA Paper 99-4818, p. 3, 4, Pieter G. Buning, TinChee Wong, Arthur D. Dilley, and Jenn L. Pao, "Predictions of Hyper-X Stage Separation Aerodynamics Using CFD," AIAA Paper 2000-4009, p. 3, 4., and David E. Reubush, "Hyper-X Stage Separation - Simulation Development and Results," AIAA Paper 2001-1802, p. 2-4.
} 
${ }^{6}$ Corpening history interview, p. 42.

7 "Report of Findings: X-43A Mishap by the Mishap Investigation Board Volume 1," May 5, 2003, p. 5-7. (This is the publicly released version without the ITAR-sensitive material.)

${ }^{8}$ Reukauf history interview, p. 45, 46, 51, 71, 72, and Corpening history interview, p. 48.

${ }^{9}$ Reukauf history interview, p. 57, 58.

${ }^{10}$ Aerospace Highlights June 10, 2004, p. 3, 4, June 25, 2004, p. 3, and July 2, 2004, p. 3.

${ }^{11}$ Ibid, August 20, 2004, p. 3 and August 27, 2004, p. 3.

${ }^{12}$ Reukauf history interview, p. 73.

13 “NASA Helps U.S. Air Force Gear Up for 2009 X-51 Flights," Space.com, September 9, 2008.

The "X-51" designation was selected for the project because it is the reverse of "X-15."

${ }^{14}$ Reukauf history interview, p. 45, 46, 71, 72. 